\title{
Self-concept as a factor in the formation of professional identity of future psychologists
}

\author{
L.V. Bura ${ }^{1 *}$, and Ya.G. Zalevskaya ${ }^{2}$ \\ ${ }^{1}$ V.I. Vernadsky Crimean Federal University, Simferopol, Russia \\ ${ }^{2}$ V.I. Vernadsky Crimean Federal University, Simferopol, Russia
}

\begin{abstract}
The article deals with the problem of forming the professional identity of future psychologists, a study of the self-concept as a factor in the formation of the professional identity of future psychologists was conducted.
\end{abstract}

\section{Introduction}

Socio-economic, scientific and technical changes taking place in modern society actualize the problem of training highly qualified personnel. This problem is especially relevant in relation to psychologists, whose activities are of high importance both for an individual and for society as a whole.

Today, the main emphasis is placed on the formation of their knowledge, skills and abilities necessary for professional activity in the system of training psychological personnel, and not enough attention is paid to the development of personal characteristics, on which the success of the future psychologist largely depends.

Among the personal qualities necessary for a psychologist in professional activity, it is necessary to note professional identity and the self-concept as one of the factors influencing its formation. Awareness of the correctness of one's own professional choice, selfacceptance as a specialist provides the future psychologist with confidence in building his own personal and professional life scenario.

Therefore, the problem of the self-concept as a factor of the professional identity of future psychologists at the stage of acquiring a profession requires special study.

\section{Research questions}

Some conceptual points are several theoretical provisions that reflect an approach to the formation of professional identity are important for our work:

- professional identity is a phenomenon of personality self-awareness (reflects a person's ideas about what he should be, what he should be able to do and how to behave in the professional community in order to be effective in his profession) and has the properties of personal identity [1];

\footnotetext{
* Corresponding author: buraselivanova.1@mail.ru
} 
- professional identity is associated with group membership (a certain small or large professional group), therefore, it has the properties of social identity: in the course of professional development, the subject identifies himself either with representatives of his profession with the appropriate professional qualities, or with himself as a professional at certain stages of development (we are talking about self-determination in a social group) [2];

- professional identity is formed in the process of professionalization [3];

- the formation of a professional identity mediated by the gradual development of the personality of a professional.

The factors contributing to the formation and development of professional identity are determined in modern psychological research. So, E.M. Ivanova and E.A. Klimov distinguish external and internal factors of the formation of professional identity. External ones mean the information environment as a source of ideas about the subject of work, ways of obtaining vocational education and the requirements of a particular profession; social environment is the demand and prestige of the profession in society. Internal factors are semantic and temporary constructions of professional experience, features of mental processes, abilities and inclinations, as well as the self-concept as an integral personal characteristic [4].

The psychological dictionary, edited by B.G. Meshcheryakov, V.P. Zinchenko, interpret the self-concept as "a developing system of the individual's ideas about himself, which contains awareness of his physical, intellectual, characterological and social qualities; subjective perception of external factors that affect their own personality; self-esteem" [5].

In the history of psychology, questions of the formation, development and measurement of the self-concept are presented in the works of foreign (R. Assagioli, R. Burns, W. James, C.H. Cooley, D. Mead, K. Rogers, G. Allport, M. Rosenberg, K. Horney) and domestic (BC Agapov, IV Baryshnikova, AA Bodalev, AV Ivashchenko, IS Kon, R.S. Panteleev, NI Sardzhveladze, V.V. Stolin, I.I. Chesnokova) researchers who defined the self-concept as a multicomponent personal education that has a number of functions:

- structuring - achieving and maintaining internal consistency and integration of experience (R. Burns) [6];

- perceptual - the perception of oneself, one's capabilities and personal qualities (K. Rogers) [7];

- the function of an individual's awareness of himself as a subject of theoretical and practical activity (S. L. Rubinstein) [8];

- control - correlating one's behavior with the norms of the social environment (A.V. Ivashchenko) [9];

- self-education (A.G. Spirkin) [10].

For the first time, the American psychologist, the founder of functionalism in psychology W. James, stated about the need to study the phenomenon of self-concept in his book "The principles of psychology" (1890). W. James divided the global, personal I (Self) into interacting I-conscious (I) and I-as-object (Me). A person, on the one hand, has consciousness, and on the other hand, he is aware of himself as one of the elements of reality [11].

Further research of the self-concept took place in the mainstream of humanistic psychology, psychoanalysis, symbolic interactionism, psychology of activity. To date, many studies are devoted to the study of the professional self-concept of future specialists, the development of the content characteristics of the self-concept of students in various areas of training and the relationship of the self-concept with other personal characteristics [12]. 


\section{Research methods}

The study used theoretical and practical methods. Theoretical one is a comparative analysis of scientific sources for understanding the phenomena of "professional identity" and "Iconcept" in various approaches, methods of generalization and systematization of theoretical material. Practical (test) methods are Personality questionnaire of A. T. Gersail [13], Methodology for studying the clarity of the self-concept of J. Campbell [14], Method for diagnosing social and psychological adaptation of K. Rogers - R. Diamond [15].

The personal questionnaire of A. T. Gersail is intended for the study of persistent internal states of the personality that affect the attitude towards other people, their work and self-attitude. The questionnaire contains 9 scales that allow assessing such parameters of the self-concept as the discrepancy between the real and ideal self, a sense of meaninglessness of existence, restlessness, etc [13].

The method of studying the clarity of the self-concept by J. Campbell allows you to determine the "clarity of ideas about oneself", which reflects the consistency, stability and certainty of a person's ideas about himself and his qualities [14].

Methodology for the diagnosis of socio-psychological adaptation by K. Rogers - R. Diamond makes it possible to assess the features of the socio-psychological adaptation of the adaptation period of the individual through the integral indicators such as "selfactivity", "adaptation", "acceptance of others", "internality", "emotional comfort", " striving for domination" [15].

\section{Findings}

The study was carried out on the basis of the Humanitarian and Pedagogical Academy (branch) of the Federal State Autonomous Educational Institution of Higher Education "Crimean Federal University named after V.I Vernadsky "in Yalta. The sample consisted of 1-2, 4-5-year students of the direction of training 37.03.01 Psychology. In the course of the study we determined the substantive characteristics of the self-concept of future psychologists of primary courses and graduates.

According to the results of the study on the personality questionnaire of A. T. Gersail (the results are presented in table 1), the indicators "Loneliness" (strong severity of the state), "Meaninglessness of existence" (moderately expressed state), "Hostile conflict" (moderately pronounced state), "Discrepancy between the real and ideal self" (strong severity of the state), "Hopelessness" and "Feeling of restlessness" (moderately expressed state) are more indicated among students of the 1 st and 2 nd courses, . We associate an increase in these indicators at the initial stages of training with changes in living conditions and environmental requirements for the individual, as a result of which there is a revision of ideas about oneself and one's capabilities; lack of communication and close relationships; primary immersion in the profession and the dynamics of their professional image of I. The adaptation process, is also especially pronounced in the first year of study. We also note an increase in the Freedom of Choice and Free Will Indicators in graduation courses, which indicates an increase in the ability to make a choice regardless of the circumstances. The indicator of "Sexual conflict" is weakly expressed both at the initial stages of education and in the final years.

After analyzing the results of the study on the method of diagnosing the sociopsychological adaptation of K. Rogers - R. Diamond (the results are presented in Table 2), we note an increase in the adaptive capabilities of the respondents by the end of training, which indicates an increase in the consistency of the requirements of the social environment and personal tendencies of the subjects. 
Table 1. Results of the study of the characteristics of the self-concept according to the personality questionnaire by A.T. Dzhersail.

\begin{tabular}{|c|c|c|}
\hline Scale & $\mathbf{1 - 2}$ courses & $\mathbf{4 - 5}$ courses \\
\hline Loneliness & 5,4 & 4,1 \\
\hline The meaninglessness of existence & 4,6 & 3 \\
\hline Freedom of choice & 6 & 6,2 \\
\hline Sexual conflict & 1,9 & 1,3 \\
\hline Hostile conflict & 3,8 & 2,9 \\
\hline Discrepancy between real and ideal self & 5,9 & 3,4 \\
\hline Free will & 4 & 4,2 \\
\hline Hopelessness & 3,7 & 3,1 \\
\hline Feeling of restlessness & 3 & 2,8 \\
\hline
\end{tabular}

An increase in the "Self-acceptance" indicators indicates an increase in the degree of satisfaction with personal qualities and an improvement in self-esteem during the period of study. The indicator of "acceptance of others" reflects the level of the individual's need for communication, interaction, joint activity. This indicator is especially significant for people of the profession "person-to-person".

We note a slight increase in this indicator. An increase in the "Emotional comfort" indicator testifies to the positive dynamics of the emotional attitude to the current reality. The indicator "Internality" (internal locus of control) reflects the ability of respondents to take responsibility for their decisions, actions and events. We have revealed a significant dynamics of this indicator in graduation courses. We also noted insignificant differences in the indicator "Striving for dominance" (leadership, leadership in solving problems).

We assessed the certainty, awareness, internal consistency and stability of the selfperceptions of the subjects using the method of studying the clarity of the self-concept of $J$. Campbell. In the initial courses, this indicator is 38 points and is characterized as the average clarity of the self-concept, in the graduating courses we note the average clarity of the self-concept, closer to high (22 points), which indicates an increase in the awareness of their personal qualities, the development of a system of ideas about yourself.

Table 2. The results of the study of the characteristics of the self-concept by the method of diagnostics of socio-psychological adaptation by K. Rogers - R. Diamond.

\begin{tabular}{|c|c|c|}
\hline Scale & $\mathbf{1 - 2}$ courses & $\mathbf{4 - 5}$ courses \\
\hline Adaptation & 53,7 & 70,1 \\
\hline Self-acceptance & 21,7 & 36 \\
\hline Acceptance of others & 14,9 & 18,7 \\
\hline Emotional comfort & 11,8 & 16 \\
\hline Internality & 17 & 26,9 \\
\hline Striving for dominance & 11 & 12,3 \\
\hline
\end{tabular}


Thus, in the course of the study, we identified the positive dynamics of the content characteristics of the self-concept of future psychologists in the process of professional education. However, we note that the presented dynamics is insufficient for the successful development of professional identity and professional formation of a future specialist. To improve the indicators of self-concept and professional identity, it is necessary to implement additional programs (trainings, workshops) aimed at developing the personal and professional development of future psychologists.

\section{Conclusions}

Summing up the above, we note that higher education has a fairly powerful potential for the formation of students' professional identity, and, at the same time, there is a serious lag in purposefully using the existing didactic tools to achieve just such goals.

Undoubtedly, the theoretical uncertainty of the essence of the phenomenon of professional identity of future psychologists does not contribute to the practical implementation in the educational process of higher education of the goal aimed at forming the professional identity of undergraduate students. At the same time, certain steps can already be taken for this, namely:

- to fill the humanitarian component of training with subjects that will lay a powerful foundation in the creation of the image of a student-psychologist, the basis of his professional self-awareness;

- relying on the principles of student-centered teaching, to ensure the activation of the student's mental resource for the effective development of educational and professional experience and the manifestation of his subject position in this process;

- to create a model for the formation of the professional identity of a future psychologist in the conditions of study at a university in order to constantly monitor the process of achieving the goal, its results and providing, if necessary, corrective measures.

\section{References}

1. L.V. Bura, Psychology of national identity in the modern youth environment, Human Sciences, 1 (49), p. 147 (2020)

2. T. Tadzhfel, D. Turner, Social identity and intergroup relations (Progress, Moscow, 1982)

3. A.R. Fonarev, Personal development in the process of professionalization, Voprosy Psychologii 6, pp. 72-83 (2004)

4. L.N. Ivanova, Professional identity and professional space, World of psychology, 2, 148-156 (2004)

5. V. P. Zinchenko; B. G. Meshcheryakov, BPS (AST, Moscow, 2014)

6. R.B. Burns, Self-concept development and education (Holt, Rinehart and Winston, London, 1982)

7. K. Rogers, Becoming a Person (Eksmo-Press, Moscow, 2002)

8. S.L. Rubinstein, Being and consciousness. Man and the world (Peter, SPb, 2003)

9. V.S. Agapov, A.V. Ivashchenko, The functions of the Ego-conception in management, RUDN University, 1, 73-87 (2003)

10. A. G. Spirkin, Consciousness and self-consciousness (Politizdat, Moscow, 1972)

11. W. James, Psychology (Pedagogy, Moscow, 1991) 
12. Ya.G. Zalevskaya, O.N. Usatenko Developing the Components of a Self-Concept in Future Psychologists with the Method of Non-Author Drawing Psychoanalysis, Advances in Social Science, Education and Humanities Research, 396, 198-202 (2020)

13. V. Ziegler-Hill, T.K. Shackelford, Encyclopedia of Personality and Individual Differences (Springer International Publishing, New York, 5849)

14. J.D. Campbell, P.D. Trapnell, Self-concept clarity: Measurement, personality correlates, and cultural boundaries, Journal of Personality and Social Psychology, 6 (70), 141-156 (1996)

15. L.N. Ivanova, Social identity and problems of education (Yaroslavl, 2001) 